\title{
A methodological note on a punishing stimulus for children'
}

\author{
P. A. FRIED ${ }^{2}$ \\ UNIVERSITY OF WATERLOO
}

\begin{abstract}
Abstraet
A stimulus whose onset, duration, and intensity are easily controlled, dilute citric acid, was proposed as a punishing stimulus for children. Results were reported which showed the punitive effect of dilute citric acid for a rewarded response in children. Problem
\end{abstract}

The literature on punishment is typified by the use of infrahumans as Ss and electric shock as the punishing stimulus (e.g. Church, 1963)。While shock may be an ideal punisher for animal behavior, since its onset, duration, and intensity can be readily controlled and manipulated, problems of administration have restricted its use with humans, especially children. Typical punishers in experiments on child behavior have been verbal signals such as "wrong" or "no" (e.g. Stephens \& Baer, 1964) or loss of a reward (e.g. Stevenson et al, 1959), both of which may be considered a type of non-reward rather than punishment and both of which are difficult to manipulate in terms of duration and intensity.

The purpose of this paper is (a) to describe a stimulus, dilute citric acid, whose onset, duration, and intensity are easily manipulated and which can be administered repeatedly to children without danger of ill effects and (b) to demonstrate that the stimulus acts as a punisher.

\section{Stimulus}

Powdered citric acid (readily available in drug stores) is mixed with water until the desired intensity of the stimulus is reached (a ratio of one part citric acid to three parts water was employed in the demonstration described below). The solution is administered to $\mathrm{S}$ on a cotton swab "Q-tip" which, when not in use, remains in the mixture. The onset and duration of administration are controlled by $\mathrm{E}$ who signals with a buzzer when $S$ is to place the swab in his mouth and tells $S$ when to remove it.

\section{Method}

Sixteen children, aged 8-9 years, whose parents had given permission for their participation in an experiment involving taste, were used as Ss. Ss were paired at random, one of each pair being assigned randomly to a punished or non-punished group. Each $S$ was required to learn to press two buttons in a particular sequence which resulted in the immediate delivery of a marble. The $\mathrm{S}$ was instructed that he could keep all the marbles he won and that he could play the game for as long as he wished. However, if while playing, he heard a buzzer he would be required to pick up the "Q-tip" in front of him and suck it like a "lollipop or sucker" until $\mathrm{E}$ told him to take it out of his mouth. All Ss were told to try the "Q-tip" once before the game started. After $\mathrm{S}$ had the swab in his mouth for $2 \mathrm{sec}$. in the proper fashion, i.e. right in his mouth, not just on his lips, E told $S$ to replace the "Q-tip" in the cup.

In both groups the occurence of three consecutive correct responses was set as the learning criterion. When the criterion was reached, Ss in the punished group received both punishment (sucking the "Q-tip" for 2 sec. as in training) and reward (a marble) for every correct response while Ss in the non-punished group received reward alone. The buzzer, which signalled punishment, was of a $0.5 \mathrm{sec}$. duration, mild in tone $(72 \mathrm{db})$, and simultaneous with the reward administration. Punishment followed within $2 \mathrm{sec}$. If $\mathrm{S}$ failed to stop the game within 25 responses $E$ stopped it. Immediately after the game all Ss were offered a drink of water.

\section{Hesults}

Every $\mathrm{S}$ in the non-punished group made the maximum number of responses (25) while Ss in the punished group gave a mean of 6.4 responses. (Wilcoxon matched-pairs, signed ranks test. $\mathrm{p}<.01$.)

\section{Discussion}

These data strongly confirm the efficacy of citric acid as a punishing stimulus. In continuing work using citric acid more than 120 Ss have been tested with only one report of side-effects, a case of mild nausea which lasted for approximately an hour.

The effectiveness, the ease of controlled administration, plus the freedom from untoward physical and psychological side-effects suggest that dilute citric acid is a suitable method of applying aversive stimuli to children in an experimental situation.

\section{Referenees}

Church, R. The varied effects of punishment on behavior. Psychol. Rev., 1963, 70, 369-402.

Stephens, J., \& Baer, J. Factors influencing the efficiency of punishment and reward: the opportunity for immediate review, and special instructions regarding the expected role of punishment. J. genet. Psychol., 1964, 65, 53-66.

Stevenson, H., Morton, W., \& Zigler, E. Discrimination learning in children as a function of motive-incentive conditions. Psychol. Rep., 1959, 5, 95-98.

\section{Notes}

1. This research was supported in part by grant APA-102 from the National Research Council.

2. The author is indebted to Dr. R. Banks and J. McMurray of the University of Waterloo and Dr. D. Cappon of the University of Toronto for their advice and assistance. 